\title{
Commentary
}

\section{Building the evidence base for sustained public health response to the opioid epidemic in Canada}

\author{
Theresa Tam, BMBS, FRCPC
}

Tweet this article

Over the past two years, the epidemic of opioid-related overdoses has been the most significant public health crisis, demanding a collective response from all levels of government working with frontline responders and other partners. Tragically, over 4000 apparent opioid-related deaths are projected for 2017, surpassing the almost 3000 deaths reported in Canada in 2016. Canadians from all socioeconomic groups and urban as well as suburban and rural communities across the country are affected. ${ }^{1}$ While western Canada has been hardest hit to date, our most recent data show the trend is increasing in other parts of the country. Turning the tide of this complex public health crisis is a priority for public health authorities at all levels of government. A strong evidence base is critical for guiding our efforts toward urgent and targeted interventions to prevent overdose deaths and address the underlying causes of problematic substance use.

The Public Health Agency of Canada (PHAC) plays an integral role in the Government of Canada's coordinated response to the opioid crisis, which is led by Health Canada's Opioid Response Team. Federal action on opioids takes a collaborative approach through targeted public health emergency response activities across four pillars: prevention, treatment, harm reduction and enforcement. Underlying all four pillars is the need for a strong evidence base to better identify trends, support decisionmaking, target interventions and monitor impacts. PHAC is currently providing leadership on two targeted epidemiological studies as well as strengthening and expanding surveillance activities for opioid-related harms in order to further our understanding of the circumstances surrounding overdose deaths across Canada. These initiatives will fill gaps in our knowledge about the risk factors and causes of opioid-related overdose fatalities, helping us inform policy decisions and develop and better target interventions. PHAC is also providing technical support to the provinces and territories by placing Public Health Officers within provincial and territorial jurisdictions to support data collection efforts and improve surveillance infrastructure. Looking ahead, PHAC aims to work with First Nations, Inuit and Métis partners to develop surveillance strategies that can address crucial gaps in our understanding of the impact of this crisis on Indigenous Canadians.

I am acutely aware that no department or government can effectively address this epidemic on its own. Intergovernmental and cross-sectoral collaboration are critical. PHAC works closely with provincial and territorial health authorities through the Special Advisory Committee on the Epidemic of Opioid Overdoses, which I co-chair with Dr. Robert Strang, Chief Medical Officer of Health of Nova Scotia. Since its creation in December 2016, the Special Advisory Committee has enabled collaboration and information sharing between jurisdictions to better support harm reduction, improved surveillance and the development of prevention and treatment strategies.

This special issue of Health Promotion and Chronic Disease Prevention in Canada: Research, Policy and Practice is dedicated to the opioid crisis. Through this publication we seek to advance our collective understanding of this epidemic in Canada, including examining available data to quantify the burden to society; describe the distribution of harms, population risk factors and trends over time; explore the context and circumstances from which the crisis has arisen; and consider promising avenues for further investigation.

Two of the articles that appear in this issue, by authors Ye et al. $^{2}$ and Orpana et al., ${ }^{3}$ estimate the burden associated with opioid harms. The article by Ye et $\mathrm{al}^{2}$ examines the contribution of drug overdose deaths to life expectancy in British Columbia. These authors estimate that during the period 2014-2016, life expectancy at birth decreased by 0.38 years and that one-third of this decline was attributable to fatal overdoses (mainly opioids). Orpana et al. $^{3}$ address opioid-related morbidity and mortality, estimating that between 1990 and 2014 the age-standardized rate of opioid-related years of life lost (YLL) increased by more than $142 \%$ in Canada while decreasing globally by $10 \%$.

Also in this issue, O'Connor et al. ${ }^{4}$ examine national and provincial trends in hospitalizations due to opioid poisonings. These authors estimate that such hospitalizations increased by more than $50 \%$ in Canada during the 10 -year period from 2007-2008 to 2016-2017. They also found that during the period from 2012-2013 to 2016-2017 the age-adjusted rate of emergency department visits due to opioid poisonings increased by more than $100 \%$ in Alberta and by nearly $50 \%$ in Ontario.

In their articles, Belzak and Halverson ${ }^{5}$ and Bozat-Emre et al. $^{6}$ consider risk factors and sociodemographic characteristics associated with opioid-related harms. Belzak and Halverson ${ }^{5}$ provide a national 
overview of what is currently known about the epidemic and touch on potential risk factors and observed variations with respect to age, sex and ethnicity. BozatEmre et al. ${ }^{6}$ use data from the Government of Manitoba's Take-Home Naloxone program to identify sociodemographic characteristics associated with the Program's users.

Guan et al. ${ }^{7}$ look at the issue of opioid prescriptions and estimate the impact of the 2016 delisting of high-strength opioids from Ontario's public drug formulary on physician prescribing patterns.

Finally, Tibebu et al. ${ }^{8}$ explore how social media data may assist us in understanding public perceptions and opinion regarding opioid use and government response.

The research findings compiled in these articles contribute to our goal of building a strong evidence base to guide planning and decision making for more precise public health action.

A second special issue of the journal dedicated to opioids will be released in September 2018. This forthcoming issue will examine risk factors in the British Columbia Provincial Overdose Cohort; explore the role of opioids in suicide deaths in Alberta and opioid-related poisonings in young people; and describe the impact of changes to opioid-prescribing policy in Nova Scotia and a strategic approach to addressing the crisis in Ontario.

As a public health community, it is critical that we continue to raise awareness of the risks associated with problematic opioid use, underscoring that this crisis continues to affect Canadians of all ages, from all backgrounds. To this end, reducing the stigma associated with problematic substance use is also of vital importance as stigma presents a serious challenge to harm reduction efforts, even where interventions are well designed. Engagement of Canadians who have lived and living experience of opioid substance use disorder, including young people and Indigenous Canadians, is a priority.

First-hand knowledge can provide valuable insights for decisionmakers, researchers, physicians and public health practitioners alike. Continued collaborative action will be the key to reversing the current trajectory of the epidemic. By continuing to work across disciplines, sectors of society and all levels of government, we will be best placed to develop effective longterm solutions to prevent further tragic loss of life and to protect the health of Canadians.

I would like to take this opportunity to acknowledge the many individuals and organizations involved in responding to this crisis; I applaud and encourage your continued efforts to reduce mortality and prevent the serious harms associated with opioid substance use disorder across the country. I am confident that these articles will greatly contribute to the growing knowledge base needed to guide and support our collective efforts.

\section{Dr. Theresa Tam}

Chief Public Health Officer of Canada

\section{References}

1. Special Advisory Committee on the Epidemic of Opioid Overdoses. National report: apparent opioid-related deaths in Canada (January 2016 to June 2017) [Internet]. Ottawa (ON): Public Health Agency of Canada; 2017. Available from: https://www.canada.ca/en /public-health/services/publications /healthy-living/apparent-opioid -related-deaths-report-2016-2017 -december.html

2. Ye X, Sutherland J, Henry B, et al. At-a-glance - Impact of drug overdose-related deaths on life expectancy at birth in British Columbia. Health Promot Chronic Dis Prev Can. 2018; 38(6):248-51.

3. Orpana HM, Lang JL, Baxi M, et al. Canadian trends in opioid-related mortality and disability from opioid use disorder from 1990 to 2014 through the lens of the Global Burden of Disease Study. Health Promot Chronic Dis Prev Can. 2018;38(6):234-43.

4. O’Connor S, Grywacheski V, Louie K. At-a-glance - Hospitalizations and emergency department visits due to opioid poisoning in Canada. Health Promot Chronic Dis Prev Can. 2018;38(6): 244-7.
5. Belzak L, Halverson J. The opioid crisis in Canada: a national perspective. Health Promot Chronic Dis Prev Can. 2018;38(6):224-33.

6. Bozat-Emre S, Marshall SG, Zhong C, et al. At-a-glance - Lessons learned from launching the Manitoba TakeHome Naloxone Program. Health Promot Chronic Dis Prev Can. 2018; 38(6):252-5.

7. Guan Q, Khuu W, Martins D, et al. Evaluating the early impacts of delisting high-strength opioids on patterns of prescribing in Ontario. Health Promot Chronic Dis Prev Can. 2018; 38(6):256-62.

8. Tibebu S, Chang VC, Drouin CA, et al. At-a-glance - What can social media tell us about the opioid crisis in Canada? Health Promot Chronic Dis Prev Can. 2018;38(6):263-7. 